Invited Commentary

\title{
Prejudice in science - Lessons from the coronavirus story
}

\section{A R T I C L E I N F O}

\section{Keywords:}

Coronavirus

Scientific publishing

Disruptive research

\begin{abstract}
A B S T R A C T
In the current pandemic times, medical physicists may not be aware that there is an interesting story on two significant discoveries related to the coronavirus. One is the invention of the polymerase chain reaction (PCR) and the other is the first electron microscopic observation and identification of the coronavirus. Both of them were disregarded by the reviewers and major journals declined to publish these discoveries. These days, PCR, for example, is a widespread method for analyzing DNA, having a profound effect on healthcare, especially now during the Covid-19 pandemic. Prejudice or perhaps ignorance prevail in every aspect of our society, and there is no exception in scientific research. We need to, however, learn from these two stories and be open-minded about novel discoveries and findings - as they may be just disruptive in the "right" way to lead to an unexpected breakthrough.
\end{abstract}

Our success as scientists is often measured in terms of publications output and/or grant success. However, impact factors and citations can be misleading, for example, when someone works in a very niche area with a very small number of scientists engaged in that particular research space.

Perhaps a more objective measure of research success is its translational impact on our society and industry. At the same time, the true realization of impact and societal consequence can take years to come to fruition and may depend on the co-development of parallel technologies or sciences.

However, the question remains: How capable are you at objectively recognizing new "disruptive" and impacting research work? Especially if it challenges your system of knowledge and convictions. Our manuscripts and grant applications are handed over to editors and reviewers with the trust that they would be able to spot/identify groundbreaking discoveries and objectively assess their merit. Unfortunately, this may not always be so.

While some cases may have gained more prominence, do you know that there is an interesting story on two significant discoveries related to the coronavirus? One is the invention of the polymerase chain reaction (PCR) and the other is the first electron microscopic observation and identification of the coronavirus.

Dr Kary Mullis, an American biochemist, developed the polymerase chain reaction (PCR), the DNA replication technique that is one of the most commonly used methods in molecular biology. Both Nature and Science rejected one of the first reports by Kary Mullis on the development of a technique which turned out to become the most widespread method for analyzing DNA [1]. The editors did not believe in this revolutionary technology that was about to modernize the DNA analysis with its practical application to everyday life and especially now during the Covid-19 pandemic. They suggested to Mullis to publish in a secondary journal. Subsequently, the paper appeared later in Methods in Enzymology [2].

Later Kary Mullis shared half of the 1993 Nobel Prize in Chemistry for his invention of the PCR. The citation says: "For contributions to the developments of methods within DNA-based chemistry" [3].

His work today has transformed health care where PCR plays a crucial role in timely COVID-19 diagnosis, impacting patient management and associated healthcare costs.

Largely forgotten by the world and scientific community until in the heat of the current pandemic is Dr. June Almeda (née Hart) [4] She was a technician, originally from Glasgow, Scotland, who never obtained formal qualifications but developed excellent electron microscopy skills on the job. She mastered and pioneered the technique to visualize the ultrastructure of viruses using a technique known as immuno-electron microscopy. She was the first to recognize a new group of viruses, the coronavirus, while researching in St. Thomas's Hospital Medical School, London.

Dr. Almeida submitted her work on the newly discovered virus, only to be met with scepticism from the reviewers who thought the images were "just poor-quality pictures of influenza virus". Subsequently, with perseverance, she managed to publish it in the Journal of General Virology 1967 [5]. This paper received only 169 citations.

In 1968, eight virologists, led by Dr. Almeida published a note in Nature and coined the name coronavirus [6]. It is interesting to note that this note managed to receive only 31 citations.

What lesson could we learn from this? Prejudice or perhaps ignorance prevail in every aspect of our society, and there is no exception in scientific research. Both Kary and June persevered to publish their discoveries despite prejudice or incorrect judgment from their peers.

Research is mounting during the Covid-19 pandemic. More than 11,770 peer-reviewed publications related to Covid-19 have been published since Jan 2020 and its rapid increase is unprecedented [7]. How many of these papers are significant to science and groundbreaking? Understandably not all of them. However, various conflicting findings, as well as accusations against unorthodox theories, were reported.

Perhaps we need to learn from these two stories and be openminded about some of those novel discoveries and findings - as they may be just disruptive enough to lead to an unexpected breakthrough. 


\section{References}

[1] Yandell K. Riding Out Rejection. How to navigate the choppy waters of scientific publication. The Sceintist, Feb 2015; 28. https://www.the-scientist.com/careers/ riding-out-rejection-35867.

[2] Mullis KB, Faloona FA. Specific synthesis of DNA in vitro via a polymerase-catalyzed chain reaction. Methods Enzymol 1987;155:335-50.

[3] https://www.nobelprize.org/prizes/chemistry/1993/summary/ [accessed 30.05. 2020].

[4] Combs S. She discovered coronaviruses decades ago-but got little recognition. National Geographic, 17 April 2020. https://www.nationalgeographic.com/history/ 2020/04/june-almeida-discovered-coronaviruses-decades-ago-little-recognition/.

[5] Almeida JD, Tyrrell DA. The morphology of three previously uncharacterized human respiratory viruses that grow in organ culture. J Gen Virol 1967;1(2):175-8. https:// doi.org/10.1099/0022-1317-1-2-175.
[6] Virology: Coronaviruses. Nature 220; 1968: 650. doi:10.1038/220650b0 [accessed 30.05.2020].

[7] http://www.covid19bibliometrics.org [accessed 30.05.2020].

Kwan Hoong $\mathrm{Ng}^{\mathrm{a}, *}$, Eva Bezak ${ }^{\mathrm{b}, \mathrm{c}}$

${ }^{a}$ Department of Biomedical Imaging, University of Malaya, Kuala Lumpur, Malaysia

${ }^{\mathrm{b}}$ Cancer Research Institute, University of South Australia, Adelaide, SA 5001, Australia

${ }^{\mathrm{c}}$ Department of Physics, University of Adelaide, Adelaide, SA 5005,

Australia

E-mail address: ngkh@ummc.edu.my (K.H. Ng).

* Corresponding author. 